\title{
A COMPARATIVE STUDY BETWEEN CONVENTIONAL HERNIOPLASTY AND LAPAROSCOPIC ASSISTED HERNIOPLASTY
}

\author{
Sunil Narang1, Sumit Shukla², Pradeep Shivsharan ${ }^{3}$
}

${ }_{1}^{1}$ Deputy Superintendent, Department of General Surgery, MGM Medical College and M Y Hospital, Indore, Madhya Pradesh.

2 Professor, Department of General Surgery, MGM Medical College and M Y Hospital, Indore, Madhya Pradesh.

${ }^{3}$ Resident Doctor, Department of General Surgery, MGM Medical College and M Y Hospital, Indore, Madhya Pradesh.

\begin{abstract}
BACKGROUND
The groin is one of the natural weak points 4 of the abdominal wall. The earliest record of inguinal hernia dates back to approx. 1500 BC. Many types of operations were done before, but it was only in the $19^{\text {th }}$ century that the inguinal canal's anatomy was well defined and the greatest contribution towards hernia surgery was by surgeon Edoardo Bassini, ${ }^{12}$ as he was the first surgeon to maintain the functional anatomy of the inguinal canal post-surgery. His method was associated with the lowest mortality and recurrence rates up till then. Therefore, he is called as "father of modern herniorrhaphy." Shouldice described multilayered repair in 1953, which was a notable improvement to Bassini's repair method. The recurrence rates in Shouldice repair was done in Shouldice hospital, Toronto, it was less than $1 \%$. Berliner and Lichtenstein ${ }^{13}$ have developed simpler and equally effective methods and are known as modern pioneers of hernia surgery.

Aims and Objectives- This study aims at comparing all aspects of laparoscopic hernioplasty with conventional hernioplasty. ${ }^{19}$

1. To compare the early complication rates in LAH and conventional hernioplasty.

2. To compare the postoperative mobilisation, duration of hospital stay, and return to work in LAH and conventional hernioplasty.
\end{abstract} ABSTRACT

\section{MATERIALS AND METHODS}

The present study is a non-randomised controlled trial of fifty cases of unilateral inguinal hernia admitted in MY Hospital during the study period from October 2016 to October 2017. I) 50 cases were selected on the basis of convenience sampling method; II) Both direct and indirect unilateral inguinal hernias were selected; iii) After pre-operative preparation, patients were randomly allocated to two groups consisting 25 in each. Group open (Lichtenstein's) and laparoscopic (TEP) repair.

\section{RESULTS}

In our study, the youngest participant was 20 years old and the oldest was 65 years old. All participants were men. The youngest patient who underwent Lichtenstein's repair was 26 years old and the oldest was 62 years old. The youngest patient who underwent TEP repair was 23 and the oldest was 60.

\section{CONCLUSION}

The gold standard for any procedure should provide a safe, cost effective and long-lasting repair with minimal morbidity and early ambulation. Lichtenstein repair provides a tension free repair, but a larger incision is used.

\section{KEYWORDS}

C-Complete, D- Direct, F- Female, IH- Inguinal Hernia, InC- Incomplete, InD- Indirect, LA- Local Anaesthesia, LAH- Laparoscopic Assisted Hernioplasty, M- Male, SAB- Subarachnoid Block.

HOW TO CITE THIS ARTICLE: Narang S, Shukla S, Shivsharan P. A comparative study between conventional hernioplasty and laparoscopic assisted hernioplasty. J. Evolution Med. Dent. Sci. 2018;7(17):2114-2117, DOI: 10.14260/jemds/2018/473

\section{BACKGROUND}

Laparoscopic transperitoneal closure of the internal orifice using metal clips was first attempted by Ger in 1977. The most popular methods done today are TAPP (Transabdominal Preperitoneal Mesh Repair) and TEP (Total Extraperitoneal Repair).

\section{TEP (Total Extraperitoneal Repair)}

First port $(10 \mathrm{~m})$ placement just below umbilicus, anterior rectus sheath is divided transversely and underlying rectus

'Financial or Other Competing Interest': None.

Submission 28-03-2018, Peer Review 12-04-2018,

Acceptance 14-04-2018, Published 23-04-2018.

Corresponding Author:

Dr. Pradeep Shivsharan,

MGM Medical College and

MYH Hospital, Indore, Madhya Pradesh.

E-mail: chill28486@gmail.com

DOI: $10.14260 / j e m d s / 2018 / 473$

\section{(c) $(1)(9)$}

muscle is then retracted laterally to access the preperitoneal space using balloon trocar. The balloon is inflated to create a working space and also helps ensure haemostasis. Second port ( $5 \mathrm{~mm}$ ) is made in midline $2 \mathrm{~mm}$ above pubic symphysis and third ( $5 \mathrm{~mm}$ ) mid-way between the two ports.

\footnotetext{
Procedure ${ }^{13,20}$

The pubic bone is identified by careful dissection, which is the first anatomical landmark. Next important landmark is the inferior epigastric artery. Next step is to identify the cord structures and separate them form our field in order to create a space for laying a mesh. One should exercise precaution to not enter the triangle of doom, injury to which can lead to torrential bleeding. Direct hernias are reduced. An indirect hernia is looked before, which lies superomedial to the deep ring. The sac after being dissected or transected is ligated using an endoloop.
} 


\section{TAPP (Transabdominal Preperitoneal Repair) ${ }^{21}$}

Technique was first described by Arregui in 1991. Pneumoperitoneum is created using a Veress needle through a sub-umbilical puncture. Pressure is maintained at 12 - 15 mmHg. A $10 \mathrm{~mm}$ port is introduced above the umbilicus and two $5 \mathrm{~mm}$ ports on either side of the umbilical port. The hernial contents are reduced. Direct and small indirect hernias are easily reduced, and large indirect inguinal hernias are dissected. A large mesh covering all three potential areas, i.e. direct, indirect and femoral is placed and fixed to the pubic fascia and cooper's ligament using EMS stapler. Mesh is covered with the peritoneal flap.

\section{Laparoscopic-Assisted Hernioplasty}

Combines the best of both approaches, that is use of endoscopic instruments that enables use of a smallest possible incision yet using a familiar anatomic approach used in conventional hernioplasty.

\section{Complications of Laparoscopic Hernia Repair}

1. Nerve injury- most commonly involved are the lateral cutaneous nerve of thigh and femoral branch of genitofemoral nerves.

2. Vascular injury- most commonly the inferior epigastric artery, spermatic vessels.

3. Injury to vas and testicular complications.

4. Long learning curve.

Laparoscopic hernioplasty has only a few added advantages over conventional hernioplasty like less post-op pain and earlier mobilisation, but with the disadvantages of a longer learning curve, complicated procedure.

\section{Objective}

- To compare the early complication rates in LAH and conventional hernioplasty.

- To compare the postoperative mobilisation, duration of hospital stay and return to work in LAH and conventional hernioplasty.

\section{Study Design}

Descriptive comparative study.

\section{MATERIALS AND METHODS}

The present study is a non-randomised controlled trial of fifty cases of unilateral inguinal hernia admitted in MY Hospital during the study period of October 2016 to October 2017. The 50 cases were selected on the basis of convenience and after pre-operative preparation the 50 patients were randomly allocated into two groups consisting 25 in Lichtenstein's repair open group and 25 in laparoscopic (TEP) repair group. Both direct and indirect unilateral inguinal hernias were selected.

Both types of surgeries were informed to the patient in their own language.

\section{Types of Outcome Measures}

a) Haematoma, b) Seroma, c) Post-operative pain, d) Length of hospital stay (days), e) Time to return to usual activities.
Source of Data/ Sampling Method and Sample Size

50 cases of unilateral direct or indirect inguinal hernia, adults, admitted to MY Hospital, Indore, MP, India. Out of these, 25 were chosen for Lichtenstein's repair and the remaining 25 for total extraperitoneal repair.

\section{Inclusion Criteria}

1. Patients presenting with inguinal hernia.

2. Patients above 20 years of age and below 65 years of age.

\section{Conventional Hernioplasty Procedure}

1. The procedure is performed under $S A B$ with all standard OT procedures.

2. A $6-8 \mathrm{~cm}$ incision is made parallel to the inguinal ligament. Incision is carried down through the Scarpa's fascia to the external oblique aponeurosis.

3. Inguinal region is explored for presence of a direct or indirect inguinal hernia. Hernial sac is mobilised, reduced and then transfixed.

4. A polypropylene mesh is cut accordingly and fixed using prolene 1-0 to the pubic tubercle. A continuous suture is taken to secure the inferior edge of the mesh to the reflected part of inguinal ligament and another continuous suture to secure the superior border to internal oblique muscle. The two free edges of the mesh are also fixed using continuous sutures keeping the mesh loose with a few wrinkles to ensure a tension-free fixation.

\section{Laparoscopic-Assisted Hernioplasty Procedure 22,23,24}

1. The procedure is performed under SAB with standard OT procedures. ${ }^{19,14,17}$

2. A $2 \mathrm{~cm}$ skin incision is made at the level of internal inguinal region and blunt dissection is done upto external oblique aponeurosis. Cord structures are separated from the inguinal ligament. A $10 \mathrm{~mm}$ laparoscopic fan retractor is inserted.

\section{Statistical Analysis}

The results of the two types of hernia repairs against the specified outcome measures were analysed with the following statistical methods: - descriptive - crosstabs - chisquare test. SPSS software was used.

\section{RESULTS}

In our study, the youngest participant was 20 years old and the oldest was 65 years old. All participants were men. The youngest patient who underwent Lichtenstein's repair was 26 years old and the oldest was 62 years old. The youngest patient who underwent TEP repair was 23 and the oldest was 60

Mean Age and Standard Deviation (Comparing Cases who Underwent Lichtenstein's Repair and TEP Repair)

\begin{tabular}{|c|c|c|}
\hline & Lichtenstein's Repair & TEP Repair \\
\hline Mean Age (in yrs.) & 47.12 & 53.04 \\
\hline SD & 13.0809 & 13.61825 \\
\hline
\end{tabular}

The ' $p$ ' value is more than 0.05 . Hence, there is no relation between the ages of the patients and the procedure they underwent. Lichtenstein's repair and TEP repair. 
Presenting Symptoms: Totally 20 patients presented with left-sided inguinal hernia as compared to 30 right-sided hernias.

\begin{tabular}{|c|c|c|}
\hline Valid & Frequency & Percentage \\
\hline $\begin{array}{c}\text { Direct inguinal } \\
\text { hernia }\end{array}$ & 27 & 54 \\
\hline $\begin{array}{c}\text { Indirect inguinal } \\
\text { hernia }\end{array}$ & 23 & 46 \\
\hline Total & $\mathbf{5 0}$ & $\mathbf{1 0 0}$ \\
\hline \multicolumn{3}{|c|}{ Type of Hernia } \\
\hline
\end{tabular}

\begin{tabular}{|c|c|c|c|}
\hline Hernia & Open Hernia & TEP & Total \\
\hline Direct & 11 & 16 & 27 \\
\hline Indirect & 14 & 9 & 23 \\
\hline Total & $\mathbf{2 5}$ & $\mathbf{2 5}$ & $\mathbf{5 0}$ \\
\hline $\begin{array}{c}\text { Association of Direct and Indirect Inguinal Hernia Patients } \\
\text { with Lichtenstein's and TEP Repair }\end{array}$ \\
\hline
\end{tabular}

' $\mathrm{P}$ ' value is more than 0.05 ; hence, it is not significant. There is no statistically significant biasing of a particular type of hernia towards a particular procedure.

\section{Duration of Symptoms}

\begin{tabular}{|c|c|c|}
\hline Valid & Frequency & Percentage \\
\hline$<1 \mathrm{y}$ & 22 & 44 \\
\hline$>1 \mathrm{y}$ & 28 & 56 \\
\hline Total & $\mathbf{5 0}$ & $\mathbf{1 0 0}$ \\
\hline \multicolumn{2}{|c|}{$\begin{array}{r}\text { Association of Direct and Indirect Inguinal Hernia Patients } \\
\text { with Lichtenstein's and TEP Repair }\end{array}$} \\
\hline
\end{tabular}

A higher number of patients presented with complaints for more than 1 year.

\begin{tabular}{|c|c|c|c|}
\hline & Direct Hernia & Indirect Hernia & Total \\
\hline Smoker & 19 & 9 & 28 \\
\hline Non-Smoker & 8 & 14 & 22 \\
\hline Total & $\mathbf{2 7}$ & $\mathbf{2 3}$ & $\mathbf{5 0}$ \\
\hline Association between Smoking and Incidence of Hernia \\
\hline
\end{tabular}

' $\mathrm{P}$ ' value is $0.03(<0.05)$, hence significant. This implies that smokers in this study had an increased incidence of direct inguinal hernia.

\begin{tabular}{|c|c|c|}
\hline Valid & Frequency & Percentage \\
\hline Strenuous work only & 23 & 46 \\
\hline Bronchial asthma only & 2 & 4 \\
\hline BPH only & 3 & 6 \\
\hline Constipation only & 2 & 4 \\
\hline COPD only & 1 & 2 \\
\hline Smoker only & 11 & 22 \\
\hline More than 1 factor & 8 & 16 \\
\hline \multicolumn{2}{|c|}{ Total Precipitating Factors } \\
\hline \multicolumn{2}{|c|}{} \\
\hline
\end{tabular}

The most important precipitating factor was strenuous work with isolated strenuous work accounting for $46 \%$ of the cases.

\begin{tabular}{|c|c|c|}
\hline Sl. No. & \multicolumn{2}{|c|}{ Mobilisation from Bed (In hrs.) } \\
\hline & $\begin{array}{c}\text { Conventional } \\
\text { Hernioplasty }\end{array}$ & $\begin{array}{c}\text { Laparoscopic Assisted } \\
\text { Hernioplasty }\end{array}$ \\
\hline 1 & 24 & 4 \\
\hline 2 & 16 & 6 \\
\hline 3 & 18 & 8 \\
\hline 4 & 20 & 4 \\
\hline 5 & 16 & 5 \\
\hline 6 & 20 & 6 \\
\hline \multicolumn{2}{|c|}{ Table 1. Mobilisation from Bed after the Procedure } \\
\hline
\end{tabular}

Early mobilisation in laparoscopic assisted hernioplasty.

\begin{tabular}{|c|c|c|c|}
\hline Surgery & $\mathbf{n}$ & $\begin{array}{l}\text { Mean } \\
\text { Days }\end{array}$ & SD \\
\hline Conventional Hernioplasty & 25 & 5.12 & 2.242 \\
\hline Laparoscopic Hernioplasty & 25 & 2.6 & 0.866 \\
\hline Total & 50 & & \\
\hline
\end{tabular}

' $\mathrm{P}$ ' value is $<0.001$, hence significant. Hence, patients who underwent conventional hernioplasty stayed for a longer time in the hospital compared to those who underwent laparoscopic hernioplasty.

\begin{tabular}{|c|c|c|c|}
\hline Type of Surgery & $\mathbf{n}$ & $\begin{array}{c}\text { Mean Time Interval } \\
\text { in (Days) of } \\
\text { Returning to Work }\end{array}$ & SD \\
\hline Conventional Hernioplasty & 25 & 43.72 & 13.8 \\
\hline Laparoscopic Hernioplasty & 25 & 25.6 & 12.1 \\
\hline \multicolumn{2}{|c|}{ Total } & $\mathbf{5 0}$ & \\
\hline \multicolumn{3}{|c|}{ Table 3. Return to Work (In Days) } \\
\hline
\end{tabular}

' $\mathrm{P}$ ' value is less than 0.05 , hence significant. Hence, patients who have undergone laparoscopic hernioplasty can go to normal work earlier than those who underwent conventional hernioplasty.

\begin{tabular}{|c|c|c|c|}
\hline Sl. No. & Complication $^{\mathbf{2 5}}$ & LAH & Conventional \\
\hline $\mathbf{1}$ & $\begin{array}{c}\text { Pain (relieved with oral } \\
\text { analgesics) }\end{array}$ & 15 & 10 \\
\hline $\mathbf{2}$ & $\begin{array}{c}\text { Pain (relieved with injectable } \\
\text { analgesics) }\end{array}$ & 4 & 15 \\
\hline $\mathbf{3}$ & Wound infections & 1 & 3 \\
\hline $\mathbf{4}$ & Bleeding & 1 & 3 \\
\hline $\mathbf{5}$ & Urinary retention & 1 & 2 \\
\hline $\mathbf{6}$ & Seroma & nil & 2 \\
\hline \multicolumn{3}{|c|}{ Table 4. Complications } \\
\hline
\end{tabular}

Complications are Higher in Conventional Method

Complications are Higher in Conventional Method
\begin{tabular}{|c|c|c|c|c|}
\hline & & \multicolumn{2}{|c|}{ Mean \pm SD } & \\
\hline Characteristics & Overall & $\begin{array}{c}\text { Lichtenstein's } \\
\text { Repair }\end{array}$ & $\begin{array}{c}\text { TEP } \\
\text { Repair }\end{array}$ & P \\
\hline Patients (n) & 50 & 25 & 25 & NS \\
\hline $\begin{array}{c}\text { Mean Age } \\
\text { (In yrs.) }\end{array}$ & $\begin{array}{c}50.09 \pm \\
12.36\end{array}$ & $\begin{array}{c}47.12 \pm \\
13.08\end{array}$ & $\begin{array}{c}53.04 \\
\pm 13.62\end{array}$ & NS \\
\hline $\begin{array}{c}\text { Direct Inguinal } \\
\text { Hernia }\end{array}$ & 27 & 11 & 16 & NS \\
\hline $\begin{array}{c}\text { Indirect Inguinal } \\
\text { Hernia }\end{array}$ & 23 & 14 & 09 & NS \\
\hline Smoker & 28 & 19 & 09 & $<0.05$ \\
\hline Non-Smoker & 22 & 08 & 14 & NS \\
\hline $\begin{array}{c}\text { Mobilisation after } \\
\text { Surgery (hrs.) }\end{array}$ & & $19.76 \_+3.28$ & $5.04+\_1.88$ & S \\
\hline
\end{tabular}




\begin{tabular}{|c|c|c|c|c|}
\hline $\begin{array}{c}\text { Duration of } \\
\text { Hospital Stay } \\
\text { (Days) }\end{array}$ & $5.12+2.24$ & $2.6+\_0.866$ & $\mathrm{~S}$ \\
\hline $\begin{array}{c}\text { Return to Work } \\
\text { (Days) }\end{array}$ & $43.72+\_13.8$ & $25.6+12.1$ & $\mathrm{~S}$ \\
\hline \multicolumn{3}{|c|}{ Table 5. Comparison of Lichtenstein's Repair Group and } \\
TEP Repair Group Patients \\
\hline
\end{tabular}

\section{DISCUSSION}

A comparative study of 25 cases of laparoscopic assisted hernioplasty and 25 of conventional hernioplasty 26 were studied and compared in Department of Surgery, MY Hospital, Indore. Pain in LAH was more easily relieved by oral analgesics, whereas that of conventional hernioplasty is more frequently required. Injectable analgesic complications were much less common in laparoscopic-assisted hernia in comparison to conventional hernioplasty. Wound infection although very rare occurred in 2 patients of conventional hernioplasty and was not seen in laparoscopic-assisted hernioplasty. Ambulation, discharge from hospital and return to work was faster in laparoscopic assisted hernioplasty. Complications were more common in conventional hernioplasty and comparatively less common in LAH.

\section{CONCLUSION}

The gold standard for any procedure should be to provide a safe, cost effective and long lasting repair with minimal morbidity and early ambulation. Lichtenstein repair provides a tension-free repair, but a larger incision is used. On the other hand, laparoscopic assisted hernia provides a similar tension-free repair with the added benefit of a smaller incision. Therefore, keeping in mind the added benefits of LAH, it should be considered a superior choice for conventional hernioplasty.

\section{REFERENCES}

[1] McVay CB. Inguinal and femoral hernioplasty: anatomical repair. Arch Surg 1948;57(4):524-30.

[2] Cooper AP. The anatomy and surgical treatment of abdominal hernia. (2 Vols). Landon: Longmans 1804 \& 1807.

[3] Fruchaud H. Anatomie Chirurgicale des Hernies de I'Aine. Paris: Doin G 1956.

[4] Condon RE. Surgical anatomy of the transverses abdominis and transversalis fascia. Ann Surg 1971;173(1):1-5.

[5] Anson BJ, McVay CB. Inguinal hernia. I. The anatomy of the region. Surg Gynecol Obstet 1938;66:186-91.

[6] Anson BJ, McCormack LJ, Cleveland HC. Aantomy of hernial regions: obturator hernia and general considerations. Surg Gynecol Obstet 1950;90(1):31-8.

[7] Anson BJ, McVay CB. The anatomy of inguinal and hypogastric regions of the abdominal wall. Anat Rec 1938;70:211-25.
[8] Anson BJ, Morgan EH, McVay CB. The anatomy of the hernia regions: inguinal hernia. Surg Gynecol Obstet 1949;89(4):417-23.

[9] Anson BJ, Morgan EH, McVay CB. Surgical anatomy of inguinal region based upon a study of 500 body halves. Surg Gynacol Obstet 1960;111:707-25.

[10] Anson BJ, Reiman AF, Swigart LL. The anatomy of the hernial regions. II. Femoral hernia. Surg Gynecol Obstet 1949;89:753-63.

[11] Clark JH, Hashimoto EI. Utilization of Henle's ligament, iliopubic tract, aponeurosis transverses bdominis and cooper's ligament in inguninalherniorrhapy. Surg Gynecol Obstet 1946;82: p. 480.

[12] Gilbert AI. Sutureless repair of inguinal hernia. Am J Surg 1992;163(3):331-5.

[13] Lichtenstein IL. Herniorrhaphy: a personal experience with 6,321 cases. Am J Surg 1987;153(6):553-9.

[14] Schultz L, Graber J, Pietrafitta J, et al. Laser laproscopic herniorrhaphy: a clinical trial preliminary results. J Laparoendosc Surg 1990;1(1):41-5.

[15] Corbitt JD. Laparoscopic herniorrhapy. Surg Laparose Endosc 1991;1(1):23-5.

[16] Dion YM, Morin J. Laparoscopic inguinal herniorrhapy. Can J Surg 1992;35(2):209-12.

[17] Sailors DM, Layman TS, Burnns RP, et al. Laproscopic hernia repair: a preliminary report. Am Surg 1993;59(2):85-9.

[18] MacFadyen BV, Arregui ME, Corbitt JD, et al. Complications of laparoscopic inguinal hernia repair. Surg Endosc 1993;7(3):155-8.

[19] Popp L. Transcutaneous aqadissection of the musculofascial defect and pre peritoneal endoscopic patch repair. J Laproendoscopic Surg 1990;1:83-90.

[20] Conner WT, Peacock EE. Some studies on the etiology of inguinal hernia. Am J Surg 1973;126(6):732-5.

[21] Darzi A, Bouchier-Hayes D, Mensizes-Gow N, et al. Endoscopically guided surface repair of inguinal hernia. Br J Surg 1995;82(4):515-7.

[22] Ger R, Monroe K, Duvivier R, et al. Management of indirect inguinal hernias by laproscopic closure of the neck of the sac. Am J Surg 1990;159(4):370-3.

[23] Ger R. The laparoscopic management of groin hernias. Cont Surg 1991;39:15-19.

[24] Hill ADK, Darzi A. Inguinal hernia: background and history. In: Drazi A, Manson JRT, eds. Laparoscopic inguinal hernia repair. Oxford: ISIS Medical Media 1994: p. 1-5.

[25] Ger R, Misshrick A, Hurwitz J, et al. et al. Management of groin hernias by laparoscopy. World J Surg 1993;17(1):46-50.

[26] Gilbert AI. An anatomic and functional classification for the diagnosis and treatment of inguinal hernia. Am J Surg 1989;157(3):331-3. 